\title{
Lumboperitoneal shunt surgery via lateral abdominal laparotomy
}

\author{
Yukihiro Goto, MD, Hideki Oka, MD, Sho Nishii, MD, Yasufumi Takagi, MD, \\ Shigeomi Yokoya, MD, PhD, and Akihiko Hino, MD, PhD
}

Department of Neurosurgery, Saiseikai Shiga Hospital, Ohhashi, Ritto City, Shiga Prefecture, Japan

\begin{abstract}
OBJECTIVE One of the technical problems encountered in performing lumboperitoneal shunt (LPS) surgery involves operative positioning of the patient. To insert the spinal catheter into the subarachnoid lumbar space, LPS is usually performed with the patient in the lateral decubitus position. However, laparotomy around the periumbilical region, especially in obese patients in the lateral decubitus position, can be quite difficult. Thus, the authors added a simple modification to the laparotomy for LPS, altering the laparotomy site to the lateral side of the patient's trunk. The aim of this study was to analyze this method in terms of technical features and outcomes.
\end{abstract}

METHODS Two LPS procedures were compared: routine periumbilical anterior abdominal laparotomy and our modified method using lateral abdominal laparotomy. The first 11 consecutive cases underwent routine anterior abdominal laparotomy with position changes or tilting of the operative bed, whereas the next 17 consecutive cases underwent lateral abdominal laparotomy not requiring position changes.

RESULTS In the anterior abdominal laparotomy group, the mean operative time was $72.36 \pm 24.63$ minutes. One patient had a spinal tube tear that required revision of the LPS 2 years postoperatively. In the lateral abdominal laparotomy group, the mean operative time was $38.82 \pm 13.87$ minutes. One patient experienced a postoperative headache and exhibited a thin, chronic subdural hematoma on imaging studies, which disappeared after adjustment of the valve pressure.

CONCLUSIONS In the current series, the operative duration was shorter in the lateral abdominal group compared with the anterior abdominal group, with no differences in complication rates. Lateral abdominal laparotomy simplifies LPS.

https://thejns.org/doi/abs/10.3171/2019.10.SPINE19957

KEYWORDS lumboperitoneal shunt; idiopathic normal pressure hydrocephalus; iNPH; lateral abdominal laparotomy; lumbar

$\mathrm{T}$ HE SINPHONI-2 multicenter prospective cohort study in Japan (multicenter trial to assess lumboperitoneal shunt [LPS] implantation in patients with idiopathic normal pressure hydrocephalus [iNPH]) showed that LPS surgery is not statistically inferior to the ventriculoperitoneal shunt (VPS) procedure in patients with iNPH..$^{10,12}$ Increasing numbers of patients have since undergone LPS..$^{15}$ LPS is an extracranial procedure that can minimize intracranial complications. ${ }^{2,7,15,18}$ While LPS does have potentially problematic features, such as tearing of the fragile spinal catheter and excessive drainage syndrome being more frequent with LPS than with VPS, $3,8,11,18$ these issues are gradually showing resolution based on the development of valve systems as well as a wide range of pressure control strategies. ${ }^{3,13,14}$
Another technical problem of LPS involves operative positioning. To insert the spinal catheter into the subarachnoid lumbar space, LPS is usually peformed with the patient in the lateral decubitus position. ${ }^{7,9,16}$ However, laparotomy around the periumbilical region in the lateral decubitus position can be quite difficult. ${ }^{916}$ Therefore, based on a combination of factors, changing the patient's position and/or tilting the operating bed to a significant degree is required in most cases. ${ }^{7,16}$ These cumbersome maneuvers are especially necessary in obese patients, and possibly a reason for surgeons choosing VPS surgery rather than LPS surgery.7.16 To overcome this drawback, we added a simple modification to the conventional LPS procedure. Few reports have described the abdominal procedure for an LPS in great detail..$^{5,9}$ Thus, in this paper we introduce an LPS method via

ABBREVIATIONS iNPH = idiopathic normal pressure hydrocephalus; $\mathrm{LPS}=$ lumboperitoneal shunt; $\mathrm{mRS}=$ modified Rankin Scale; $\mathrm{NPH}=$ normal pressure hydrocephalus; VPS = ventriculoperitoneal shunt.

SUBMITTED August 14, 2019. ACCEPTED October 11, 2019.

INCLUDE WHEN CITING Published online December 20, 2019; DOI: 10.3171/2019.10.SPINE19957. 
TABLE 1. Patient characteristics in the routine (anterior) LPS group

\begin{tabular}{|c|c|c|c|c|c|c|}
\hline Case No. & Age (yrs), Sex & Disorder & $\mathrm{BMI}\left(\mathrm{kg} / \mathrm{m}^{2}\right)$ & $\begin{array}{l}\text { Postop FU } \\
\text { (mos) }\end{array}$ & $\begin{array}{l}\text { Surgical Time } \\
\text { (mins) }\end{array}$ & Complications \\
\hline 1 & $15, \mathrm{M}$ & $\mathrm{NPH}$ due to head trauma & 19.2 & 37 & 108 & None \\
\hline 2 & $57, \mathrm{~F}$ & iNPH & 22.8 & 34 & 82 & None \\
\hline 3 & $60, \mathrm{M}$ & $\mathrm{NPH}$ due to SAH & 17.3 & 43 & 131 & None \\
\hline 4 & $66, \mathrm{M}$ & $\mathrm{NPH}$ due to SAH & 25.8 & 31 & 70 & None \\
\hline 5 & $73, \mathrm{M}$ & iNPH & 24.7 & 37 & 60 & None \\
\hline 6 & $73, \mathrm{M}$ & iNPH & 24.2 & 31 & 55 & Tear of spinal tube \\
\hline 7 & $74, \mathrm{~F}$ & $\mathrm{NPH}$ due to head trauma & 22.7 & 26 & 65 & None \\
\hline 8 & $78, F$ & $\begin{array}{l}\text { NPH due to metastatic brain } \\
\text { tumor }\end{array}$ & 20.8 & 27 & 70 & None \\
\hline 9 & $79, \mathrm{~F}$ & iNPH & 22.5 & 26 & 58 & None \\
\hline 10 & $81, F$ & iNPH & 21.4 & 26 & 50 & None \\
\hline 11 & $87, \mathrm{~F}$ & $\mathrm{NPH}$ due to SAH & 20.6 & 35 & 47 & None \\
\hline Mean (SD) & $67.55(19.55)$ & & $22.0(2.37)$ & $32.09(5.38)$ & $72.36(24.63)$ & \\
\hline
\end{tabular}

$\mathrm{FU}=$ follow-up; $\mathrm{SAH}=$ subarachnoid hemorrhage.

lateral abdominal laparotomy. We aimed to analyze our method in terms of technical features and outcomes. Our modification of the routine LPS method simplifies the procedure and may make it more widely acceptable.

\section{Methods \\ Study Population}

We compared two LPS procedures: one using routine periumbilical anterior abdominal laparotomy, and the other lateral abdominal laparotomy. Twenty-eight patients who underwent LPS surgery in our institution from January 2016 to December 2018 were assessed retrospectively. All patients were confirmed to not have obstructive hydrocephalus, based on their normal intracranial pressure as determined by spinal lumbar puncture, and were diagnosed as having communicating normal pressure hydrocephalus (NPH). All patients received preoperative lumbar MRI and CT to detect the lumbar subarachnoid space and lumbar vertebral osseous changes. All patients underwent LPS under general anesthesia utilizing a Strata adjustable pressure valve (Medtronic Inc.) or CODMAN CERTAS Plus programmable valve with SiphonGuard system (Codman Neuro). Initial valve pressure was determined based on the patient's body weight and height, and was then adjusted depending on their activities and clinical manifestations as documented by periodic outpatient visits.

\section{Anterior Abdominal Laparotomy}

The first 11 consecutive cases (Table 1) underwent LPS with anterior abdominal laparotomy; each patient was given the anterior abdominal laparotomy and a midpoint skin incision in the lateral abdominal wall, after lumbar puncture. We used a passer to guide a catheter between the lumbar puncture site and the midpoint skin incision on the patient's lateral abdominal wall. We then tilted the operating bed horizontally to perform an anterior abdominal laparotomy around the periumbilical region. In those with obesity, we generally had to change the patient's position from lateral to supine and redrape the surgical field. After laparotomy, the Strata adjustable pressure valve was inserted into the abdominal fat tissue between the midpoint skin incision and the anterior abdominal wall.

\section{Lateral Abdominal Laparotomy}

For the last 17 consecutive cases (Table 2), we applied our lateral abdominal laparotomy modification. This laparotomy does not require skin incision at the anterior abdominal wall as with the routine LPS procedures (Figs. 1 and 2). We made a small skin incision between the tenth costal inferior edge and the anterior superior iliac spine (Fig. 1, left), and then divided the muscles with a blunt dissector. After lumbar puncture, we set the CODMAN CERTAS Plus programmable valve with the SiphonGuard system between the puncture site and the laparotomy site without changing the patient's position or tilting the operating bed.

All procedures performed in this study were in accordance with the ethical standards of our institutional and national research committee and with the 1964 Helsinki Declaration and its later amendments or comparable ethical standards. This study also obtained approval from the ethics committee of our institution. Written informed consent was obtained from all individual participants and/or their first-degree relatives, prior to inclusion in the study.

\section{Results}

In the anterior abdominal laparotomy group, all patients experienced symptomatic improvement and none showed deterioration of their activities postoperatively according to the modified Rankin Scale (mRS). The mean operative duration $( \pm \mathrm{SD})$ was $72.36 \pm 24.63$ minutes. The average postoperative follow-up was $32.09 \pm 5.38$ months. One patient had a spinal tube tear necessitating LPS revision 2 years postoperatively. In the lateral abdominal 
TABLE 2. Patient characteristics in the lateral abdominal laparotomy group

\begin{tabular}{|c|c|c|c|c|c|c|}
\hline Case No. & Age (yrs), Sex & Disorder & $\mathrm{BMI}\left(\mathrm{kg} / \mathrm{m}^{2}\right)$ & Postop FU (mos) & $\begin{array}{l}\text { Operative Time } \\
\text { (mins) }\end{array}$ & Complications \\
\hline 1 & $49, \mathrm{M}$ & NPH due to head trauma & 16.7 & 26 & 57 & Excessive drainage \\
\hline 2 & $56, \mathrm{M}$ & $\mathrm{NPH}$ due to SAH & 26.0 & 12 & 63 & None \\
\hline 3 & $57, \mathrm{M}$ & $\mathrm{NPH}$ due to SAH & 24.1 & 20 & 32 & None \\
\hline 4 & $66, \mathrm{M}$ & $\mathrm{NPH}$ due to SAH & 20.5 & 17 & 35 & None \\
\hline 5 & $68, M$ & $\mathrm{NPH}$ due to SAH & 24.7 & 13 & 77 & None \\
\hline 6 & $71, \mathrm{~F}$ & $\mathrm{NPH}$ due to SAH & 18.0 & 12 & 30 & None \\
\hline 7 & $73, \mathrm{M}$ & iNPH & 25.1 & 12 & 34 & None \\
\hline 8 & $75, \mathrm{~F}$ & $\mathrm{NPH}$ due to head trauma & 26.7 & 19 & 28 & None \\
\hline 9 & $75, M$ & iNPH & 22.5 & 18 & 37 & None \\
\hline 10 & $77, \mathrm{~F}$ & iNPH & 24.1 & 18 & 29 & None \\
\hline 11 & $78, \mathrm{M}$ & iNPH & 16.1 & 11 & 30 & None \\
\hline 12 & $79, \mathrm{M}$ & iNPH & 24.5 & 15 & 40 & None \\
\hline 13 & $79, \mathrm{M}$ & iNPH & 24.8 & 20 & 24 & None \\
\hline 14 & $79, \mathrm{M}$ & iNPH & 25.7 & 12 & 44 & None \\
\hline 15 & $81, \mathrm{~F}$ & iNPH & 18.7 & 11 & 25 & None \\
\hline 16 & $85, \mathrm{~F}$ & iNPH & 26.5 & 14 & 38 & None \\
\hline 17 & $88, M$ & iNPH & 20.9 & 12 & 37 & None \\
\hline Mean (SD) & $72.71(10.25)$ & & $22.68(3.41)$ & $15.41(4.12)$ & $38.82(13.87)$ & \\
\hline
\end{tabular}

laparotomy group, all patients experienced symptomatic improvement and none showed deterioration of their activities after surgery according to the mRS. The mean operative duration was $38.82 \pm 13.87$ minutes. The average postoperative follow-up was $15.41 \pm 4.12$ months. One patient had a postoperative headache and exhibited a thin, chronic subdural hematoma on imaging studies, which disappeared after adjustment of the valve pressure. No pa- tients in either group complained of severe postoperative pain at the surgical site.

\section{Discussion}

LPS does not require an intracranial surgical procedure and surgeons do not need to be concerned about intracerebral hemorrhage related to catheter insertion into the lat-

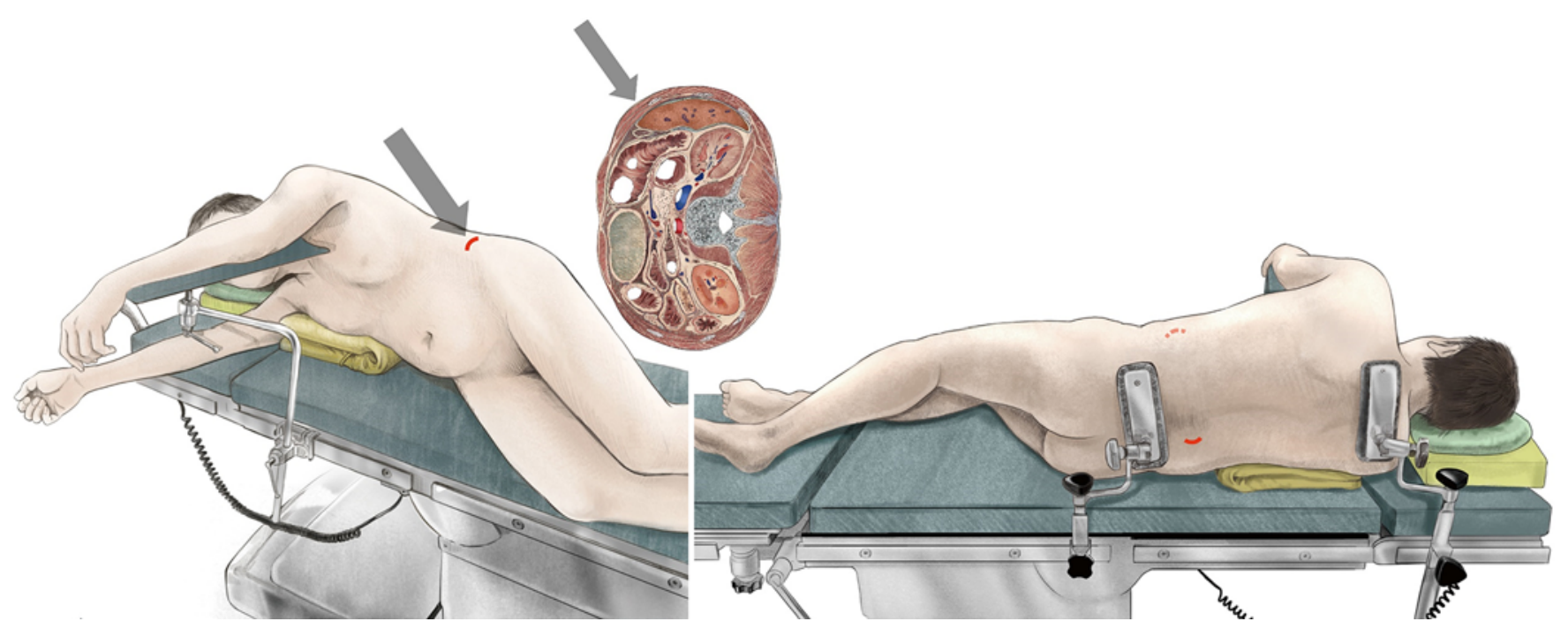

FIG. 1. Anterior (left) and posterior (right) views, and the axial plane of the abdomen at the third lumbar vertebral level (center). The red line on the left figure indicates the skin incision for the lateral abdominal laparotomy and the arrow indicates the vertical trajectory to the peritoneum. The red line on the right figure indicates the skin incision for manipulating the lumbar catheter and valve system, and the red dotted line indicates the skin incision for lateral abdominal laparotomy on the opposite side. Figure is available in color online only. 

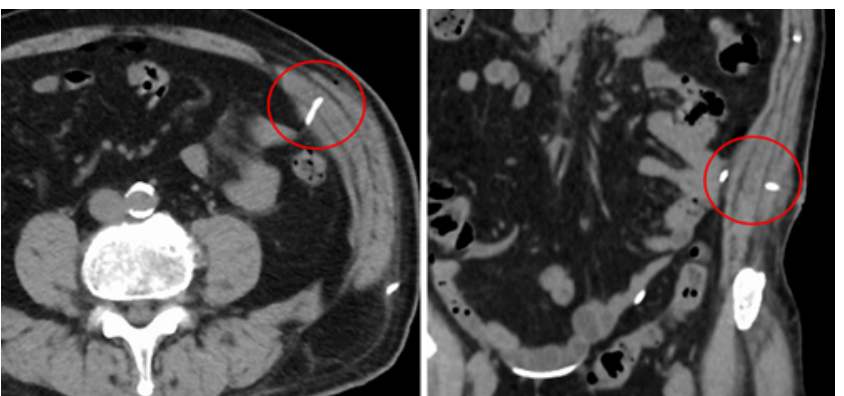

FIG. 2. Postoperative axial (left) and coronal (right) abdominal CT scans. The red circles indicate the distal catheter penetrating the lateral abdominal muscles. Figure is available in color online only.

eral ventricle. ${ }^{2,7,18}$ However, the majority of neurosurgeons still avoid LPS, because certain unfavorable features of this procedure have been reported. ${ }^{8,11,18}$ In the current series, 1 patient had a spinal tube tear that required revision surgery 2 years after the LPS procedure. Collision of osseous spinous processes might be related to tearing of the spinal catheter, and we now insert the catheter through the interlaminar space using a paramedian lumbar puncture. Low-pressure syndrome due to excessive drainage is another reported potential drawback of LPS. ${ }^{3,8,11,18}$ However, the development of valve systems now allows a wide range of pressure control, such that this problem is gradually being overcome. ${ }^{3,13,14}$

Another practical problem encountered in performing LPS insertion involves anterior abdominal laparotomy, which is the approach selected for routine LPS surgery.7,16 This procedure requires that surgeons change the patient's position or tilt the operating bed, and these maneuvers are especially necessary in obese patients, because the abdominal fat around the umbilicus is difficult to control in the lateral decubitus position. ${ }^{9,16}$ These cumbersome steps prolong the operation. Lateral abdominal wall laparotomy has several advantages over anterior abdominal laparotomy: it can be performed with the patient in the lateral position, and never requires either a position change or bed tilting. This approach achieves a much shallower surgical field because abdominal fat is effectively shifted downward to the umbilicus in the lateral position, and only two small skin incisions are required. In the current series, the operative time was significantly shorter for the lateral abdominal group (Fig. 3) than for the anterior abdominal group, and there were no statistically significant differences in age, BMI, or complication rates between the two groups. Even when the 2 patients who required repositioning were removed from the analysis (patients 1 and 3, Table 1), because repositioning and redraping are highly time-consuming, the same results were obtained.

Lateral abdominal laparotomy is a simple and easily reproducible method, but there are pitfalls. Here we provide tips based on our experience. The lateral abdominal wall consists of three muscle layers: external oblique, internal oblique, and transverse abdominal. These three muscle layers lack the tough fascia of the anterior abdominal muscle and can easily be divided with a blunt

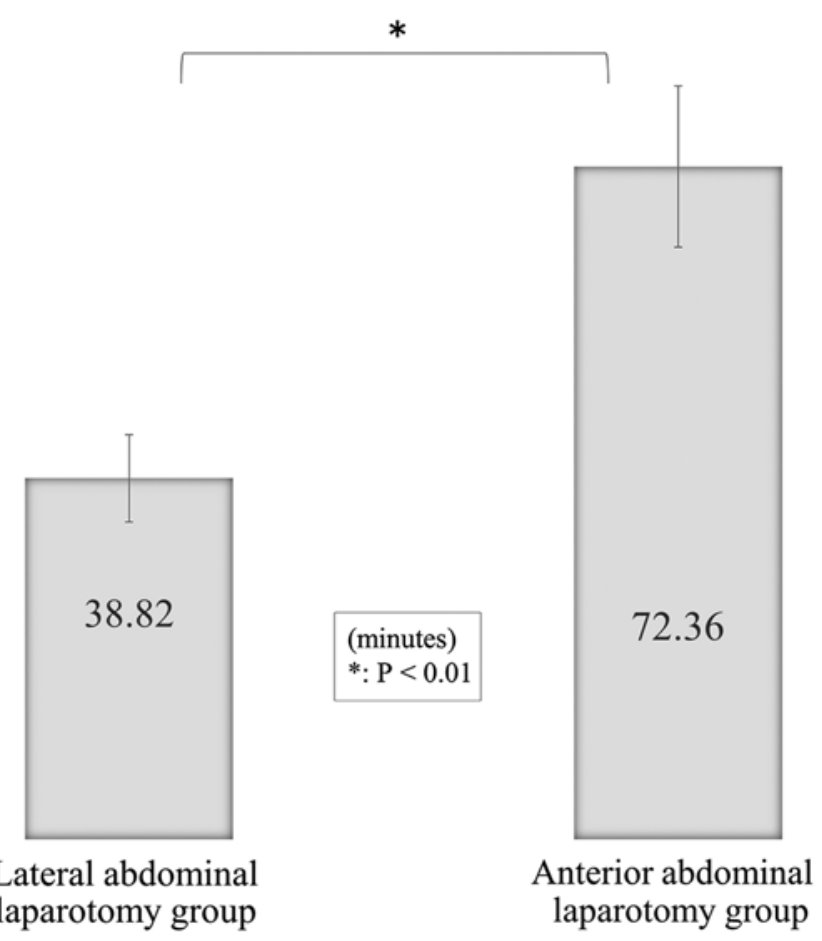

FIG. 3. Bar graphs showing the average ( \pm standard deviation) operative times for each LPS surgery.

dissector. The peritoneal layer is clearly observed after division of these muscle layers. Based on our own experiences, to perform lateral abdominal laparotomy, we do not recommend elevating the subcutaneous tissue excessively as this may easily tear the connections between muscle layers and produce a large pocket in the extraperitoneal space, possibly preventing maintenance of the vertical and shortest trajectory between the skin and the peritoneum (Fig. 4). Surgeons should keep in mind that in the lateral position, with abdominal fat shifting downward to the umbilicus, the distance from the skin to the peritoneum is no more than $10 \mathrm{~cm}$, even in obese patients. Furthermore, surgeons should also approach the center of the trunk; if the procedure is attempted in the wrong direction regarding the peritoneal layer, especially one tangential to the peritoneum, there is a risk of reaching the retroperitoneal space.

Most patients who underwent LPS via lateral abdominal laparotomy had the potential to leave the hospital within a few days after surgery without postoperative pain. However, there was no statistically significant difference between the two groups in postoperative hospital stays. This might be due to patients being hospitalized for somewhat longer periods after surgery in Japan based on the national healthcare system. Although we did not use laparoscopy in this study, there are reports describing the use of laparoscopy in LPS. ${ }^{1,4,6,17}$ Although the advantages of our method include its simplicity, less equipment required, and short operative duration, the use of adjunctive laparoscopy might be a reasonable approach, especially for patients with a past history of abdominal surgery. 


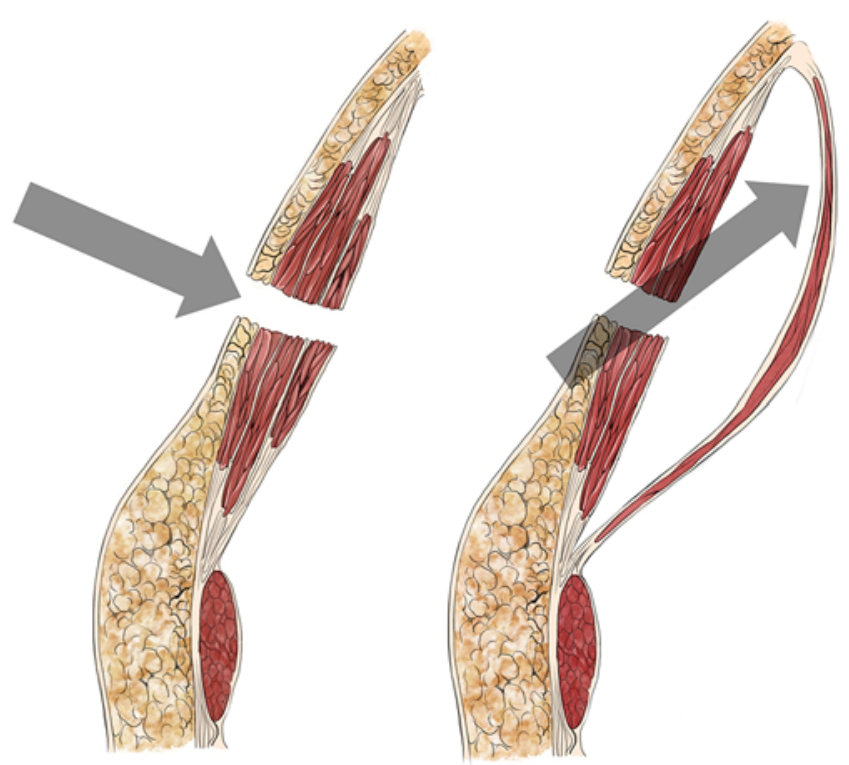

FIG. 4. Left: This figure shows the correct approach when performing lateral abdominal laparotomy. The arrow indicates the vertical trajectory to the peritoneum. Right: This figure shows an incorrect way to perform lateral abdominal laparotomy, in which the arrow indicates the tangential direction to the peritoneum. Excessive elevation of the subcutaneous tissue can result in tearing connections between muscle layers and thereby produce a large pocket in the extraperitoneal space, which may prevent maintaining the vertical and shortest trajectory between the skin and the peritoneum. Figure is available in color online only.

\section{Limitations}

The limitations of this study include the small number of patients and its retrospective nature. Another limitation is the short follow-up period. Although the complication rate in the current series was acceptable as compared with those in previous studies, a longer period is needed to assess our conclusions.

\section{Conclusions}

The number of LPS procedures performed for patients with iNPH has been increasing in recent years. In this study we have described a lateral abdominal laparotomy approach, which does not require changing the patient's position during the surgery. This approach greatly simplifies LPS surgery, potentially making this approach more widely acceptable to surgeons.

\section{Acknowledgments}

We thank Dr. Masahiro Tujiura (MD, PhD, Department of Gastroenterological Surgery, Saiseikai Shiga Hospital) for advice on how to correctly access the lateral peritoneal space in the first few cases.

\section{References}

1. Aoki T, Ayuzawa S, Matsuo R, Hosoo H, Tanno S, Miki S, et al: [Laparoscopy-assisted ventriculoperitoneal and lumboperitoneal shunt surgery.] No Shinkei Geka 40:511-517, 2012 (Japanese)

2. Barcia-Mariño C, González-Bonet LG, Salvador-Gozalbo L,
Goig-Revert F, Rodríguez-Mena R: [Lumboperitoneal shunt in an outpatient setting for the treatment of chronic hydrocephalus in adults. A study and follow-up of 30 cases.] Rev Neurol 49:300-306, 2009 (Spanish)

3. Chang CC, Kuwana N, Ito S: Management of patients with normal-pressure hydrocephalus by using lumboperitoneal shunt system with the Codman Hakim programmable valve. Neurosurg Focus 7(4):e8, 1999

4. Hammers R, Prabhu VC, Sarker S, Jay WM: Laparoscopicassisted lumboperitoneal shunt placement for idiopathic intracranial hypertension. Semin Ophthalmol 23:151-155, 2008

5. He J, Jin X, Zhang X, Kong J, Lin Y, Wu Z, et al: Use of pneumoperitoneal puncture for peritoneal catheter placement in lumboperitoneal shunt surgery: technical note. World Neurosurg 103:391-394, 2017

6. Johna S, Kirsch W, Robles A: Laparoscopic-assisted lumboperitoneal shunt: a simplified technique. JSLS 5:305-307, 2001

7. Kanazawa R, Ishihara S, Sato S, Teramoto A, Kuniyoshi N: Familiarization with lumboperitoneal shunt using some technical resources. World Neurosurg 76:347-351, 2011

8. Karabatsou K, Quigley G, Buxton N, Foy P, Mallucci C: Lumboperitoneal shunts: are the complications acceptable? Acta Neurochir (Wien) 146:1193-1197, 2004

9. Kawahara T, Higashi T, Tokimura H, Arita K, Atsuchi M, Takasaki K: Use of blunt scalp hooks for abdominal procedure in lumboperitoneal shunt placement: technical note. Neurol Med Chir (Tokyo) 54:552-553, 2014

10. Kazui H, Miyajima M, Mori E, Ishikawa M: Lumboperitoneal shunt surgery for idiopathic normal pressure hydrocephalus (SINPHONI-2): an open-label randomised trial. Lancet Neurol 14:585-594, 2015

11. Kuwana N, Kuwabara T: Lumbar subarachnoid-peritoneal shunt-follow-up study on 158 cases. Neurol Med Chir (Tokyo) 24:485-489, 1984

12. Miyajima M, Kazui H, Mori E, Ishikawa M: One-year outcome in patients with idiopathic normal-pressure hydrocephalus: comparison of lumboperitoneal shunt to ventriculoperitoneal shunt. J Neurosurg 125:1483-1492, 2016

13. Miyake H: Shunt devices for the treatment of adult hydrocephalus: recent progress and characteristics. Neurol Med Chir (Tokyo) 56:274-283, 2016

14. Miyake H, Kajimoto Y, Murai H, Nomura S, Ono S, Okamoto Y, et al: Assessment of a quick reference table algorithm for determining initial postoperative pressure settings of programmable pressure valves in patients with idiopathic normal pressure hydrocephalus: SINPHONI subanalysis. Neurosurgery 71:722-728, 2012

15. Mori E, Ishikawa M, Kato T, Kazui H, Miyake H, Miyajima M, et al: Guidelines for management of idiopathic normal pressure hydrocephalus: second edition. Neurol Med Chir (Tokyo) 52:775-809, 2012

16. Shimizu S, Hagiwara H, Hattori S, Nakayama K, Fujii K: Change of patient position using a transportation board during lumboperitoneal shunting. Technical note. Neurol Med Chir (Tokyo) 49:175-178, 2009

17. Sosin M, Sofat S, Felbaum DR, Seastedt KP, McGrail KM, Bhanot P: Laparoscopic-assisted peritoneal shunt insertion for ventriculoperitoneal and lumboperitoneal shunt placement: an institutional experience of 53 consecutive cases. Surg Laparosc Endosc Percutan Tech 25:235-237, 2015

18. Wang VY, Barbaro NM, Lawton MT, Pitts L, Kunwar S, Parsa AT, et al: Complications of lumboperitoneal shunts. Neurosurgery 60:1045-1049, 2007

\section{Disclosures}

The authors report no conflict of interest concerning the materi- 
als or methods used in this study or the findings specified in this paper.

\section{Author Contributions}

Conception and design: Goto, Oka. Acquisition of data: Goto, Oka, Nishii, Takagi, Yokoya. Analysis and interpretation of data: Goto, Oka, Nishii, Takagi, Yokoya. Drafting the article: Goto. Critically revising the article: Hino. Reviewed submitted version of manuscript: Goto. Approved the final version of the manuscript on behalf of all authors: Goto. Statistical analysis: Goto, Yokoya. Administrative/technical/material support: Oka, Yokoya, Hino. Study supervision: Goto, Oka.

\section{Correspondence}

Yukihiro Goto: Saiseikai Shiga Hospital, Shiga Prefecture, Japan. yoursongmysong@hotmail.com. 